\title{
Evaluating the fish aggregation effect of wind turbine facilities by using scientific echo sounder in Nanlong wind farm area, western Taiwan
}

Ting-Chieh Huang

National Taiwan Ocean University, Taiwan, ROC

Hsueh-Jung Lu

National Taiwan Ocean University, Taiwan, ROC, hjlu@email.ntou.edu.tw

Jia-Rong Lin

National Taiwan Ocean University, Taiwan, ROC

Shih-Hsuan Sun

National Taiwan Ocean University, Taiwan, ROC

Kou-Wei Yen

Marine Fisheries Division, Fisheries Research Institute, Taiwan, ROC

See next page for additional authors

Follow this and additional works at: https://jmstt.ntou.edu.tw/journal

Part of the Fresh Water Studies Commons, Marine Biology Commons, Ocean Engineering Commons, Oceanography Commons, and the Other Oceanography and Atmospheric Sciences and Meteorology Commons

\section{Recommended Citation}

Huang, Ting-Chieh; Lu, Hsueh-Jung; Lin, Jia-Rong; Sun, Shih-Hsuan; Yen, Kou-Wei; and Chen, Jing-Yi (2021) "Evaluating the fish aggregation effect of wind turbine facilities by using scientific echo sounder in Nanlong wind farm area, western Taiwan," Journal of Marine Science and Technology. Vol. 29: Iss. 2, Article 11.

DOI: $10.51400 / 2709-6998.1084$

Available at: https://jmstt.ntou.edu.tw/journal/vol29/iss2/11

This Research Article is brought to you for free and open access by Journal of Marine Science and Technology. It has been accepted for inclusion in Journal of Marine Science and Technology by an authorized editor of Journal of Marine Science and Technology. 
Evaluating the fish aggregation effect of wind turbine facilities by using scientific echo sounder in Nanlong wind farm area, western Taiwan

\section{Authors}

Ting-Chieh Huang, Hsueh-Jung Lu, Jia-Rong Lin, Shih-Hsuan Sun, Kou-Wei Yen, and Jing-Yi Chen 


\title{
Evaluating the Fish Aggregation Effect of Wind Turbine Facilities by using Scientific Echo Sounder in Nanlong Wind Farm Area, Western Taiwan
}

\author{
Ting-Chieh Huang ${ }^{a, b}$, Hsueh-Jung Lu ${ }^{a, c, *}$, Jia-Rong Lin ${ }^{a}$, Shih-Hsuan Sun ${ }^{\text {, }}$ \\ Kou-Wei Yen ${ }^{b}$, Jing-Yi Chen ${ }^{d}$ \\ ${ }^{a}$ National Taiwan Ocean University, 202, No.2, Beining Rd., Keelung, Taiwan \\ ${ }^{\mathrm{b}}$ Marine Fisheries Division, Fisheries Research Institute, 199, He 1st Rd., Keelung, Taiwan \\ ${ }^{c}$ Center of Excellence for the Oceans, National Taiwan Ocean University, 202, No.2, Beining Rd., Keelung, Taiwan \\ d Academia Sinica, 128, Academia Road, Section 2, Nankang, Taipei, Taiwan
}

\begin{abstract}
During the stages of construction and operation of the wind power facilities, fishery and fishery resources in the wind farm areas will certainly be changed greatly. One of the major concern is the aggregation effect of wind turbines facility. We use scientific echo sounder together with scuba diving to survey fish aggregations in the wind farm areas. In order to obtain echoes very near the facility, we use tilt beam angle instead of traditional vertical one. Variation of target strength varies while using tilted beam angle were discussed both by $e x$-situ and in-situ experiment. In $e x$-situ experiment, we measured TS of sample fish in different attacking beam angle in three different rotation planes, and conducted by setting four different beam angles to detect free-swimming fishes in a cage. We found that fish length estimated by different title angle varied greatly, but maintained linear relationship with target strength at tilt angle of $30^{\circ}$ and $60^{\circ}$. In in-situ experiment, we developed a special trackline for acoustic survey using $60^{\circ}$ tilt beam angle together with scuba diving observation to evaluate fish aggregation effect among two wind turbines, a wind tower and a neighboring artificial reefs in the Nanlong wind farm. The results showed that in the core area $(<20 \mathrm{~m})$ near the facilities the target strength distribution patterns and values were consistent with the fish length distribution from scuba diving data. In the joint surveys, we observed that the wind turbines had relatively better fish aggregation effect than nearby neighboring wind towers and artificial reefs.
\end{abstract}

Keywords: Offshore wind power, Scientific echo sounder, Scuba diving, Target strength

\section{Introduction}

$\mathrm{D}$ ue to the depletion of non-renewable energy sources and greenhouse gases that have caused global warming, countries are actively developing renewable energy, of which wind power is one of the fastest growing type [3]. According to the 21st Century Renewable Energy Policy Network (https://www.ren21.net/) released in 2020, The share of supply met by renewables reached historic highs in China, Europe, India and the United States. In China, wind and solar power generation increased $1 \%$ and $12 \%$ respectively. In the EU and the United Kingdom, while renewables delivered $46 \%$ of all power generation, up $8 \%$ compared to 2019 . The UK $4 \mathrm{C}$ offshore website (http://www.4coffshore.com/) announced top 20 sea area in the world with the best wind conditions in 2012, 16 of which are located in the Taiwan Strait, and the conditions of 
offshore wind farm are excellent. It is a very good opportunity for Taiwan, which has extremely limited onshore space, so in Taiwan government's renewable energy development policy, wind power has become a key direction of alternative energy [2]. According to the $4 \mathrm{C}$ offshore website, the power generation efficiency of the offshore wind farm is higher than that of the onshore wind farm, and the total potential wind power in Taiwan can reach 150 gigawatts (https://web3. moeaboe.gov.tw/). The development of offshore wind power can provide more economic development and job opportunities for Taiwan's wind power industry, including electrical, steel and fleet development and other related industries [29].

Taiwan government planned to construct a thousand of wind turbines in the western offshore area where is traditional fishing ground. Many conflicts between fishery and wind farm have to be face with and among them fish aggregating effect by wind power facilities is a positive effect that deserves attention. For example, Wilhelmsson et al [30]. conducted a study on the benefits of fish gathering and the impact of fish populations in offshore wind farm. They found that the species richness and biological index in the wind farm area and adjacent areas were not different, but the fish school structure near the wind turbine was different, and the fish abundance was higher. The studies of De Troch [4] and Hooper [11] both pointed out that the offshore wind farm also had the effect of like Fish Aggregating Device (FAD).

Reubens et al [24]. pointed out that there is no significant difference in the abundance between the Atlantic cod (Gadus morhua) and Pouting (Trisopterus luscus) between the stations inside and outside the wind farm area, also pointed out that there is no evidence that the wind farm area have an ecological trap effect. Dunlop et al [5]. conducted a study on the influence of the current of submarine cable in offshore wind farm, and the results showed that there was no significant difference between the existing amount of the submarine cable and the area away from the cable. Hvidt et al [12]. compare the abundance of fish inside and outside the Danish offshore wind farm, and found that although there is a slightly higher trend in the wind farm, there is no significant difference.

According to the above researches, there is no consistent conclusion on the fish aggregating effect of offshore wind farm, but it has different effects with regional and community types. During the early stage of the offshore wind farm construction in western Taiwan, fishery activities are prohibited, therefore it is impossible to evaluate fish aggregating effect of individual constructed wind turbine by fishery dependent method. Scientific echo sounder is one of the best choices because it has direct, three-dimensional, fast, and non-destructive characteristics $[19,23,26]$, which is the most convenient and objective method in many fishery-independent survey methods for assessing the effect of fish populations. The general acoustic surveys were carried out by vertical beam detection. However, the survey area is limited when general acoustic survey is applied because a research vessel has to keep a safe distance from the marine structure. In such circumstance, it is necessary to replace the traditional vertical beam with a tilt beam $[7,16]$, with which the safety of navigation increased and the relationship between fish schools and wind turbines can be better detected (Fig. 1). Rodríguez et al [25]. pointed out that the backscattering strength received from horizontal detection will cause considerable differences and this change may affect result of the resource assessment.

In the early development stage of the offshore wind farm in the Taiwan Strait, to collect fishery independent proof to fish aggregating effect of newly constructed wind power facilities is important. The objective of this study is to develop an acoustic survey method in near wind power facility and validate the method. We conducted both $e x$-situ and in-situ surveys in this study to evaluate change of the echo intensity under different beam angles through ex-situ experiments to find suitable detection angle. In the in-situ experiment, we developed a special trackline surrounding target facilities in the wind farm area for joint acoustic and scuba diving surveys. The fish aggregation effect of wind turbines, wind power and artificial reef in the offshore wind farm area were investigated and the credibility of the acoustic data was verified by scuba diving.

\section{Materials and Methods}

\subsection{Ex-situ survey (tank experiments)}

In order to understand the possible problem arose from a horizontal beam angle, two experiments were designed to detect target strength (TS) for freeswimming fish and suspended fish, respectively. Simrad EY60 echosounder with split-beam $200 \mathrm{kHz}$ transducer (nominal angle of $7^{\circ}$ ) were used in both ex-situ and in-situ experiment in this study. The parameters settings of acoustic system for tank experiment are listed in Table 1, while the water 


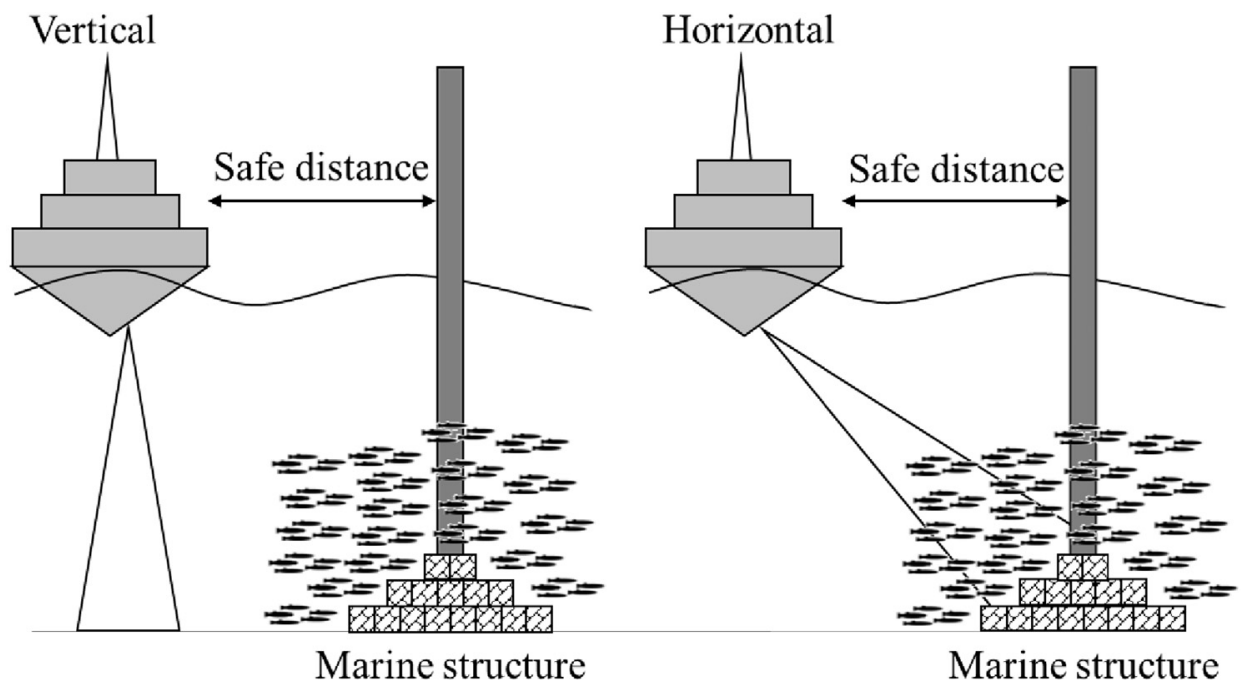

Fig. 1. The difference of navigation safety between vertical and horizontal beams when conducting valid detection for fish associated with marine structure.

Table 1. Acoustic parameters of Simrad EY60 system setting for tank experiments for suspended fish and free swimming fish

\begin{tabular}{lll}
\hline Parameter & Setting & Unit \\
\hline Ping interval & 2 & $\mathrm{ping} / \mathrm{s}$ \\
Frequency & 200 & $\mathrm{KHz}$ \\
Absorption coefficient & 0.0838 & $\mathrm{~dB} / \mathrm{m}$ \\
Sound Velocity & 1537.4 & $\mathrm{~m} / \mathrm{s}$ \\
Transducer gain & 26.5 & $\mathrm{~dB}$ \\
Transmitted pulse length & 0.064 & $\mathrm{~ms}$ \\
Power & 100 & watt \\
Two-Way beam angle & -20.1 & $\mathrm{~dB}$ \\
Minor axis 3 dB beam angle & 6.74 & degree \\
Major axis 3 dB beam angle & 6.82 & degree \\
Minor axis 3 dB offset angle & -0.07 & degree \\
Major axis 3 dB offset angle & 0 & degree \\
\hline
\end{tabular}

temperature and salinity are $26.3^{\circ} \mathrm{C}$ and $31 \mathrm{psu}$, respectively. We used black seabream (Acanthopagrus schlegelii) for the tank experiments, because it is highly tolerant to changes in temperature and salinity and is widely distributed in near shore area.

In the case of suspended fish, we measured TS values while rotating the fish in rolling, yawing and pitching plane. There were 8 black seabreams with fork length from 7.0 to $22.9 \mathrm{~cm}$ (Table 2) for TS measurement. A rotator was set on the top of the tank and the fish were anesthetized under it then control angle of incidence beam by the rotator (Fig. 2A). The three orientations to detect every $10^{\circ}$

Table 2. Size information of black seabream used for tank experiments

\begin{tabular}{llll}
\hline Experiment & \multicolumn{2}{l}{ Fork length $(\mathrm{cm})$} & Fish numbers \\
\cline { 2 - 3 } & Range & Mean $( \pm$ SD) & \\
\hline Suspended fish & $7.0-22.9$ & $13.76 \pm 6.6$ & 8 \\
Free swimming fish & $14.9-23.4$ & $19.54 \pm 1.9$ & 30 \\
\hline
\end{tabular}

and collect 30 seconds of data at a time. All TS values obtained in every incident angle (every $10^{\circ}$ ) were averaged to represent the TS of that incident angle for the fish. A total of $360^{\circ}$ clockwise rotation is performed.

In the free-swimming fish experiment, we used beam angles of $0^{\circ}$ (horizontal), $30^{\circ}, 60^{\circ}$ and $90^{\circ}$ (vertical) degrees to detect free-swimming fish. We used two tanks in this experiment (Fig. 2B and C) to measure TS for 30 fish with fork length from 14.9 to $23.4 \mathrm{~cm}$ (Table 2). The TS for these fish were measured one by one. Each fish was put into the cage after measuring its fork length, and the detection time for each fish was 10 minutes. Linear regression equations as follow were then established for each tilt angle situation after every average TS for the 30 fish were determined:

$T S=a \times \log (F L)+b$

TS: target strength $(\mathrm{dB})$

a, b: constant

FL: fork length $(\mathrm{cm})$

\subsection{In-situ experiment}

The in-situ experiment were conducted in Nanlong wind farm area located in Maoli County, Taiwan, where water depth is between 20 to $45 \mathrm{~m}$. As shown in Fig. 3, there are four related wind farm facilities, namely wind tower, offshore wind turbine\#1, offshore wind turbine\#2 and artificial reef. The wind tower was built in August, 2016, and two wind turbines were constructed and operation in October, 2016. 
(A)

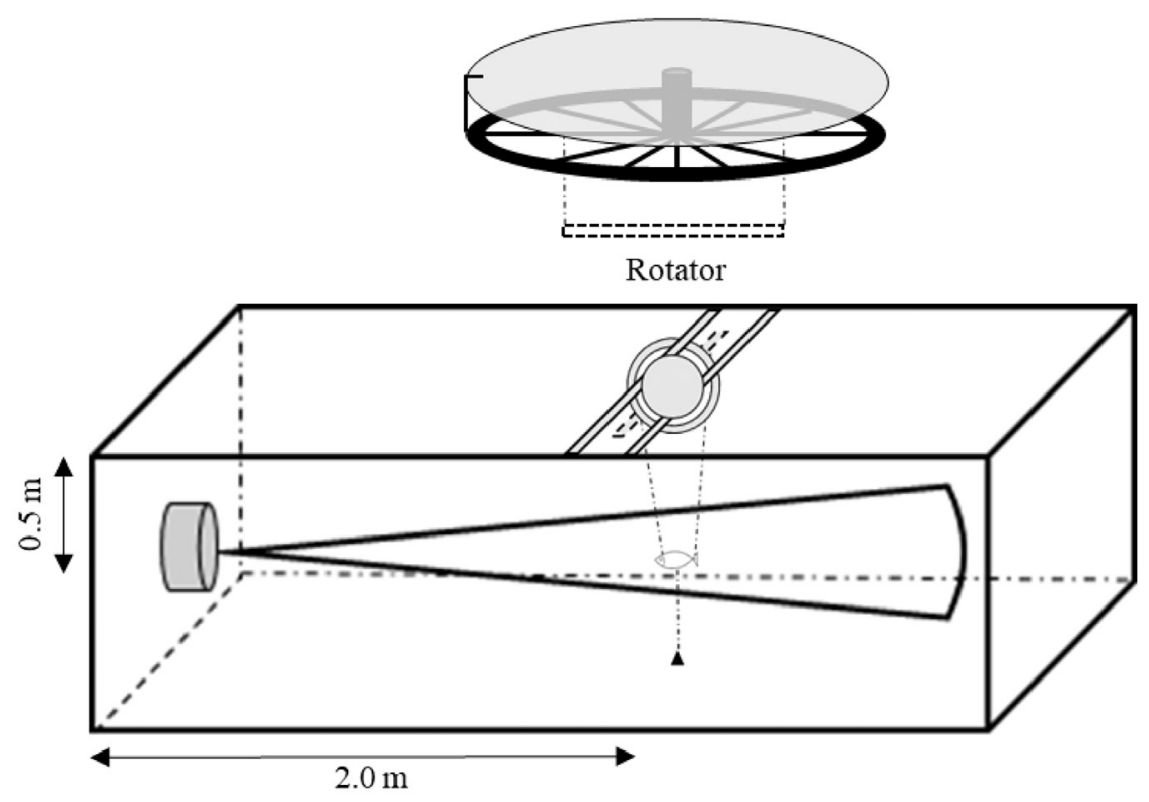

(B)

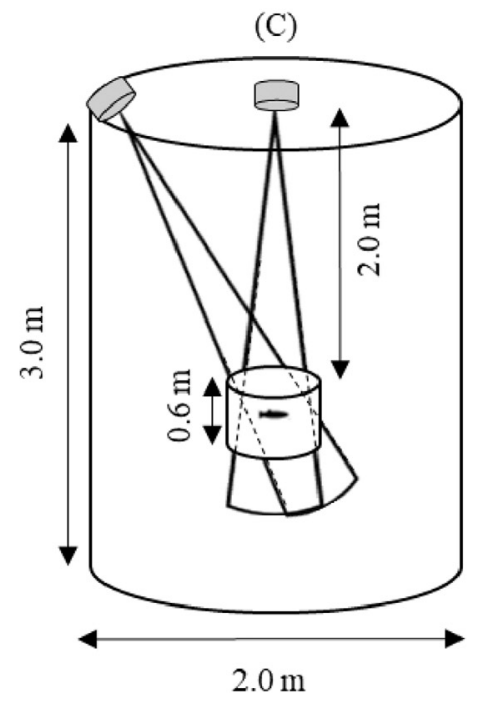

Fig. 2. Two tanks setting for ex-situ experiments. (A) suspended fish experiment setting. (B) free-swimming fish experiment for tilt angles of $0^{\circ}$ and $30^{\circ}$. (C) free-swimming fish experiment for tilt angles of $60^{\circ}$ and $90^{\circ}$.

We have two joint surveys, one during 8-9th June, 2017 and the other during 17-18 ${ }^{\text {th }}$ Aug., 2017. The scuba diving observations were conducted simultaneously within $20 \mathrm{~m}$ away from the center of the facility, and the observation was mainly photography, and visual observation records. In order to facilitate the comparison with scuba diving data, we conduct surveys with 10 pings per second, and average the TS values within the scuba diving area. Three to four divers as a group observed and recorded samples in the waterproof record book. The data items recorded are the species, number and visual estimation of fish length using method by Harvey et al [10].

Fig. 4 showed the route designed for acoustic survey with which we can detected the facilities three times from different direction. Due to fishing within the radius of $500 \mathrm{~m}$ from the wind power facilities was prohibited by law, the length of the three tracklines in Fig. 4 were set at 1000 m. An FRP fishing boat with length of $12.55 \mathrm{~m}$ and gross tonnage of 18.35 tons was used in this study. Speed was maintained at 3-4 knot during the acoustic survey. The acoustic system is also Simrad EY60 


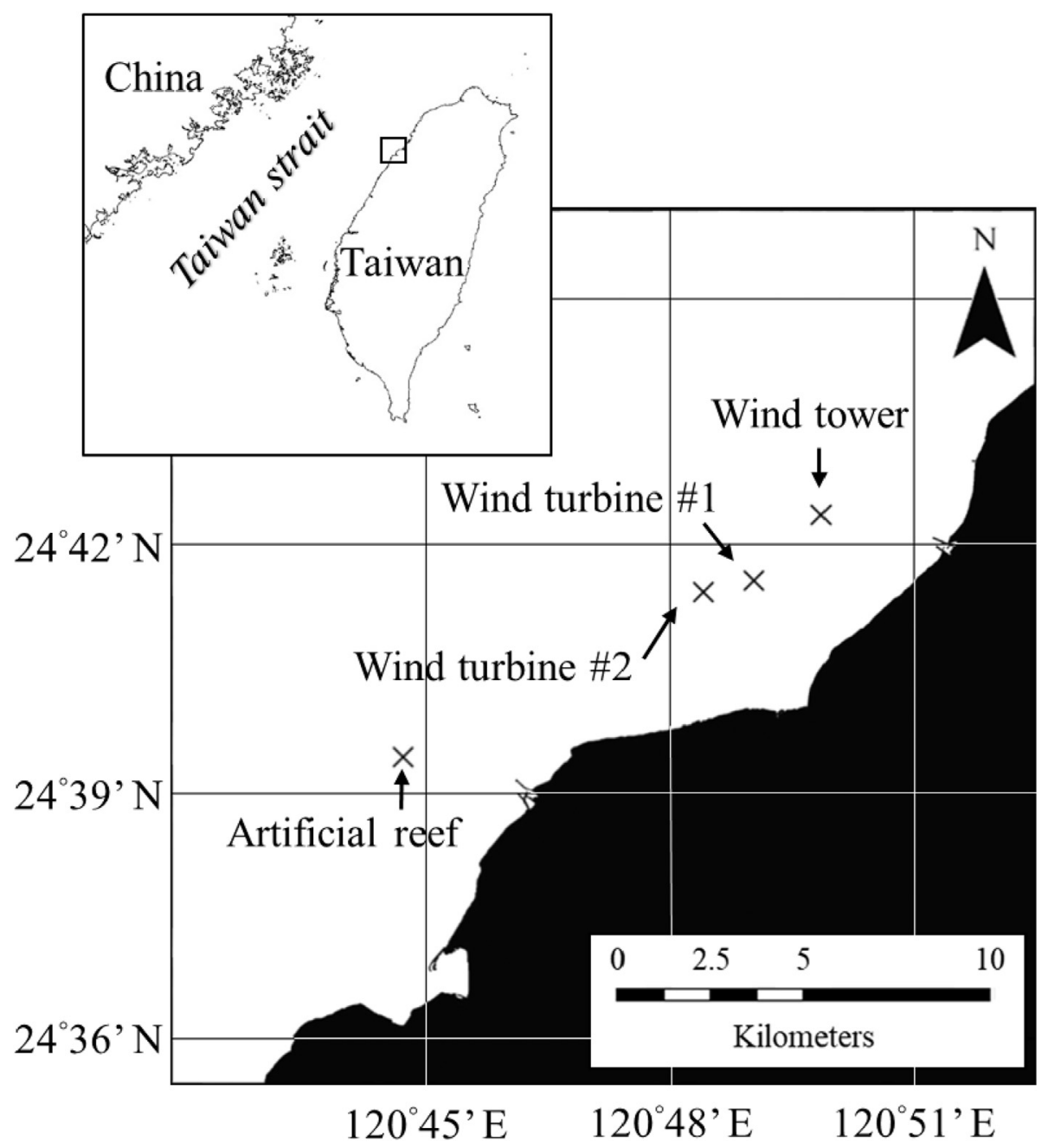

Fig. 3. Locations of the four facilities for acoustic and scuba diving surveys in Nanlong wind farm area, Taiwan.

echosounder and the parameters are as Table 3. Transducer was mounted at the port side of the vessel using pole mounts at a depth of $1.5 \mathrm{~m}$ below the surface. The direction of transmitted beam is perpendicular to the trackline in horizontal and $60^{\circ}$ tilt down from surface in vertical.

The Sv threshold is set to $-65 \mathrm{~dB}$ to facilitate comparison between different facilities. Echoes data water shallower than $3 \mathrm{~m}$ is excluded due to susceptible to bubbles and noise interference from the ship. Zooplankton and non-biological echo, such as gill nets, bubble from diver, facilities and etc, is excluded manually. The average volume backscattering for a given range from a facility were calculated by Equation (2):

$$
\overline{S v}=10 \log \left(\frac{\sum_{i=1}^{n} \gamma_{i} 10^{\frac{S v_{i}}{10}}}{\sum_{i}^{n} \gamma_{i}}\right)
$$

i: index of ESDU (elementary sampling distance unit, $50 \mathrm{~m}$ ) Marchal et al [22].

$\mathrm{n}$ : Total number of ESDU

$\gamma_{i}$ : if 0 for the each ESDU without samples, otherwise 1.

$\mathrm{Sv}_{\mathrm{i}}$ : mean $\mathrm{Sv}$ in each ESDU

$\overline{S v}$ : mean Sv of total ESDU

\section{Results}

\subsection{Estimated lengths by different attacking beam} angles

In suspended fish experiment, we measured TS for 8 fish of different lengths by different angle of incidence. Fig. 5 show a general situation of TS variation in different rotation plane. In rolling plane, the TS by ventral and dorsal are much lower than by sides (Fig. 5A). In pitching plane, the TS are relatively stable in all directions (Fig. 5B). In yawing 


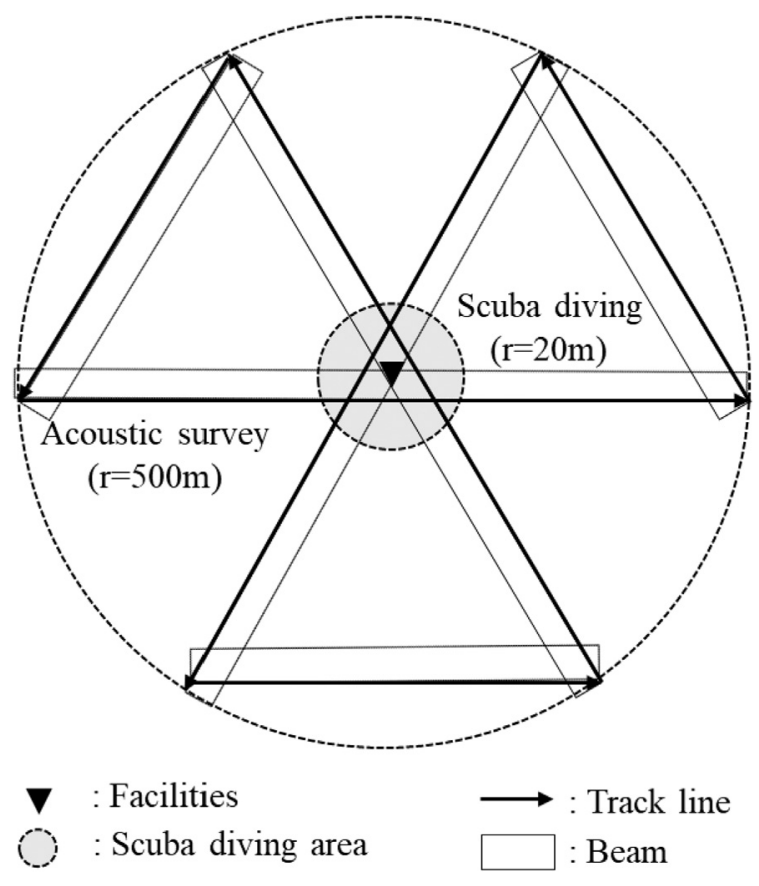

Fig. 4. Special track line designed for acoustic survey with 3 passes through the facilities (wind turbines, wind tower or artificial reef), total track line is $3 \mathrm{nmi}$. Scuba diving observations were conducted within $20 \mathrm{~m}$ around the facilities.

plane, the TS by sides are higher than by head and tail (Fig. 5C). Fig. 5 can also be found that when pitching plane, TS variation is mainly affected by fish length, and when rolling and yawing plane, in addition to the fish length, the different attacking beam angle will also cause the TS variation.

In free-swimming experiment, we measured TS for 30 fish of different lengths by different attacking beam angle. Fig. 6 shows the linear regulation result of different attacking beam angle and mean TS. At $0^{\circ}$, the linear relationship does not exist. At $30^{\circ}$ and $60^{\circ}$, both R-square are higher than $0.9(<0.01)$ and the slope is high. At $90^{\circ}$ (traditional), it has a better

Table 3. Acoustic parameters of Simrad EY60 system setting for in-situ survey

\begin{tabular}{lll}
\hline Parameter & Setting & Unit \\
\hline Ping interval & 10 & $\mathrm{ping} / \mathrm{s}$ \\
Frequency & 200 & $\mathrm{KHz}$ \\
Absorption coefficient & 0.0782 & $\mathrm{~dB} / \mathrm{m}$ \\
Sound Velocity & 1538.7 & $\mathrm{~m} / \mathrm{s}$ \\
Transducer gain & 25.6 & $\mathrm{~dB}$ \\
Transmitted pulse length & 0.256 & $\mathrm{~ms}$ \\
Power & 100 & watt \\
Two-Way beam angle & -20.6 & $\mathrm{~dB}$ \\
Minor axis 3 dB beam angle & 6.74 & degree \\
Major axis 3 dB beam angle & 6.82 & degree \\
Minor axis 3 dB offset angle & -0.07 & degree \\
Major axis 3 dB offset angle & 0 & degree \\
\hline
\end{tabular}

linear relationship with lower slope. Therefore, it is feasible to adopt tilt beam angle detection to replace vertical detection when necessary.

\subsection{Comparison between acoustic and scuba diving}

As shown in Table 4, fish length observed in the artificial reef is mostly between 5 and $10 \mathrm{~cm}$, but in wind tower, wind turbine \#1 and wind turbine \#2, fish length were mostly less than $5 \mathrm{~cm}$. In wind tower, the fish species sighted were highest (32), while in the artificial reef the species (12) sighted were the lowest. Tables 5 and 6 shows the species composition observed by scuba diving at the four facilities, in which the most species are Chromis fumea and Neopomacentrus cyanomos respectively. Fig. 7 indicated that the length distributions estimated by acoustic are generally consistence with those estimated by scuba diving. In artificial reef

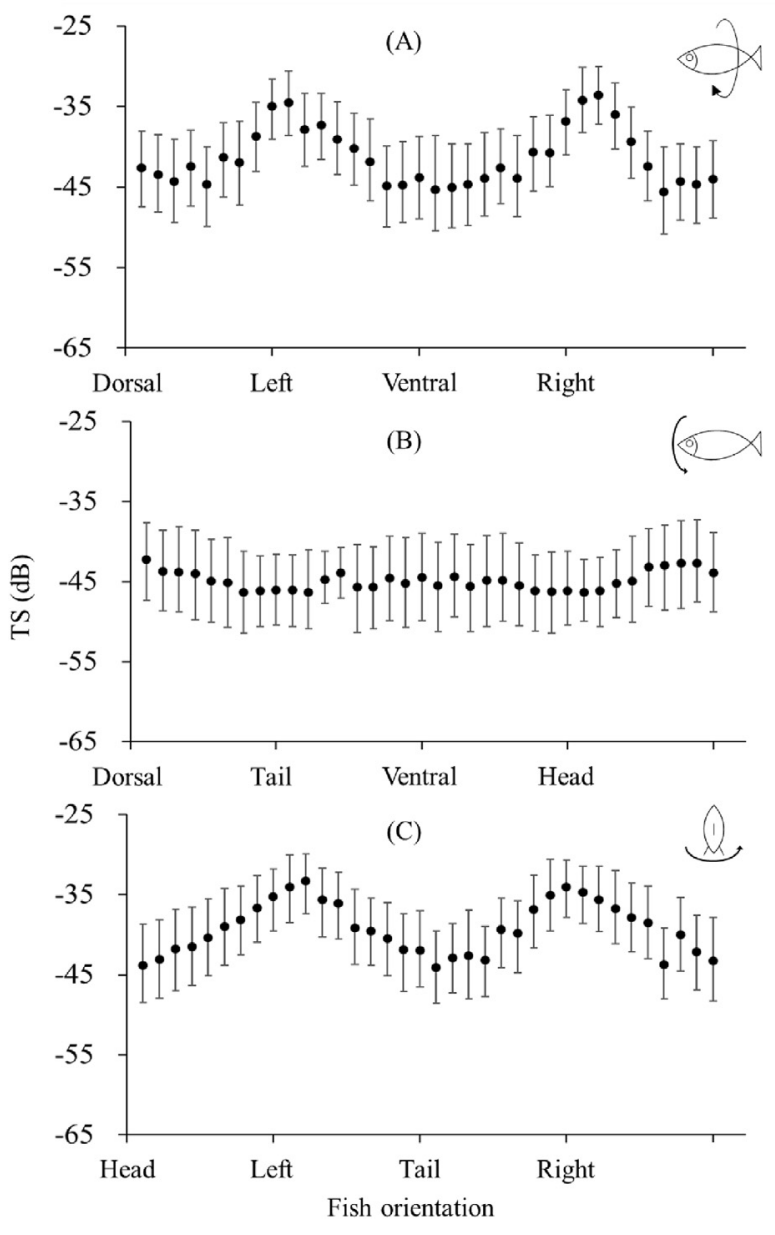

Fig. 5. TS variation in different rotation plane (real fish from $14.9 \mathrm{~cm}$ to $23.4 \mathrm{~cm}$ ), error bars represent the maximum and minimum value. (A) rolling plane, relative to dorsal; (B) pitching plane, relative to dorsal; $C$ : yawing plane, relative to head. 


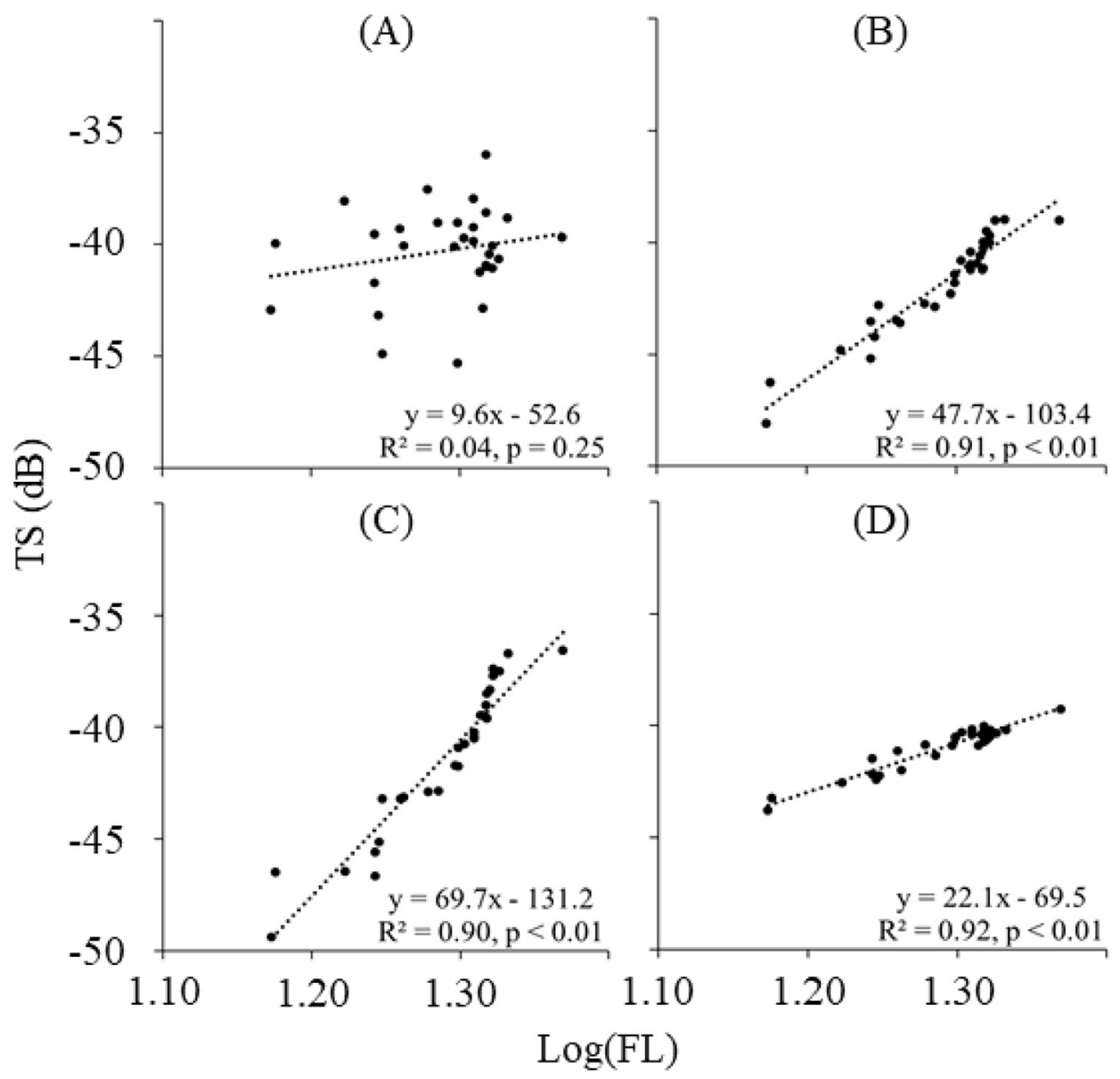

Fig. 6. Linear regression of Equation (1) between TS obtained from tank experiment by different tilt angles and $\log (F L)(N=30)$. (A) $0^{\circ}$; (B) 30 $;(C)$ $60^{\circ} ;(D) 90^{\circ}$.

and wind turbine\#2, the relationship between the TS and the scuba diving observations is basically the same.

\subsection{Fish aggregation effects evaluated by acoustics}

Both wind turbines have relatively high mean $\mathrm{Sv}$ values in ranges of $20 \mathrm{~m}$ and $500 \mathrm{~m}$, followed by the wind tower, and the artificial reef has lowest mean Sv (Fig. 8). According to the two in-situ acoustic

Table 4. Estimated number of fish, fish length and number of species by scuba diving observation at four facilities in wind farm area

\begin{tabular}{lllll}
\hline $\begin{array}{l}\text { Fish length } \\
(\mathrm{cm})\end{array}$ & $\begin{array}{l}\text { Artificial } \\
\text { reef }\end{array}$ & $\begin{array}{l}\text { Wind } \\
\text { tower }\end{array}$ & $\begin{array}{l}\text { Wind } \\
\text { turbine\#1 }\end{array}$ & $\begin{array}{l}\text { Wind } \\
\text { turbine\#2 }\end{array}$ \\
\hline$<5$ & 65 & 745 & 251 & 134 \\
$5-10$ & 70 & 288 & 132 & 62 \\
$10-15$ & 57 & 103 & 16 & 1 \\
$15-20$ & 18 & 0 & 1 & 0 \\
$20-25$ & 0 & 0 & 0 & 0 \\
$>30$ & 1 & 2 & 1 & 0 \\
Total & 211 & 1138 & 401 & 197 \\
Total species & 12 & 32 & 21 & 15 \\
\hline
\end{tabular}

surveys, it is obvious that the effect of the two wind turbines on fish aggregation is better than that of wind tower and artificial reef.

\section{Discussion and Conclusion}

Fish always to produce more yawing action than rolling and pitching, because fish like to change direction when swimming. Horizontal beam may always cause higher variation of TS (Figs. 5 and 6). The drastic changes of TS in the rolling can be attributed to the swimming behavior of the fish, which leads to a loss of linear relationship in the horizontal direction [16].

In the special environment (shallow waters, marine structures), limit of detection range and navigation safety may cause in capability of traditional echo sounding. Changing the attacking beam angle of transducer will be a good solution $[14,15,17]$. In the process of changing beam angle from vertical to horizontal, backscattering echo will be change from dorsal part to lateral part of a fish. In traditional 
Table 5. Species composition obtained by scuba diving observation at four facilities in wind farm area during 8-9th June

\begin{tabular}{|c|c|c|c|c|}
\hline Species & Artifical reefs & wind tower & wind turbine\#1 & wind turbine\#2 \\
\hline Apogonichthyoides cathetogramma & & & 1 & 2 \\
\hline Apogon semilineatus & & 2 & & \\
\hline Rhabdamia gracilis & & 100 & & \\
\hline Decapterus sp. & & & 1 & \\
\hline Trachurus japonicus & & & 1 & \\
\hline Chaetodon modestus & 1 & 3 & 1 & 1 \\
\hline Coradion altivelis & 1 & & & \\
\hline Heniochus acuminatus & 1 & 8 & 2 & 1 \\
\hline Goniistius zonatus & 1 & & & \\
\hline Diodon holocanthus & 2 & 9 & 3 & 1 \\
\hline Platax teira & & 1 & 3 & \\
\hline Parapristipoma trilineatum & 10 & 100 & 30 & 5 \\
\hline Plectorhinchus pictum & & 1 & 1 & \\
\hline Microcanthus strigatus & & 1 & & \\
\hline Choerodon azurio & & & 2 & \\
\hline Halichoeres poecilepterus & & 1 & & \\
\hline Halichoeres scapularis & & & & 1 \\
\hline Labroides dimidiatus & 1 & 2 & & 1 \\
\hline Leiognathus spp. & & 200 & & \\
\hline Lutjanus argentimaculatus & & 4 & & \\
\hline Lutjanus fulviflamma & & 5 & 3 & 1 \\
\hline Lutjanus monostigma & & 11 & & \\
\hline Pterocaesio digramma & & 60 & & \\
\hline Scolopsis vosmeri & & 6 & 2 & 1 \\
\hline Oplegnathus fasciatus & & 1 & & \\
\hline Chaetodontoplus septentrionalis & 1 & 2 & & \\
\hline Pomacanthus semicirculatus & & 1 & & \\
\hline Abudefduf sexfasciatus & & & 10 & \\
\hline Abudefduf vaigiensis & & & 10 & \\
\hline Chromis fumea & 10 & 300 & 5 & 10 \\
\hline Neopomacentrus cyanomos & 1 & 300 & 10 & 10 \\
\hline Scatophagus argus & & 1 & & \\
\hline Dendrochirus zebra & & 1 & & \\
\hline Pterois radiata & & 1 & & \\
\hline Pterois volitans & & 1 & & \\
\hline Sebastiscus marmoratus & & 2 & & \\
\hline Cephalopholis boenak & & 7 & 8 & 6 \\
\hline Diploprion bifasciatum & & & 1 & 1 \\
\hline Epinephelus areolatus & 1 & 1 & & \\
\hline Epinephelus awoara & & 1 & 1 & \\
\hline \multicolumn{5}{|l|}{ Epinephelus malabaricus } \\
\hline Grammistes sexlineatus & & 1 & & \\
\hline Pseudanthias squamipinnis & & 4 & & \\
\hline Siganus fuscescens & 1 & & 1 & 1 \\
\hline Tripterygiidae gen. spp & & & 8 & 10 \\
\hline
\end{tabular}

Table 6. Species composition obtained by scuba diving observation at four facilities in wind farm area during 17-18th Aug

\begin{tabular}{|c|c|c|c|c|}
\hline Species & Artifical reefs & wind tower & wind turbine\#1 & wind turbine\#2 \\
\hline Apogon aureus & & 6 & & \\
\hline Apogon cathetogramma & & & & 1 \\
\hline Archamia dispiluss & & 30 & & \\
\hline Selaroides leptolepis & & 50 & 20 & 3 \\
\hline Coradion altivelis & 1 & & & \\
\hline Heniochus acuminatus & 6 & 5 & 6 & 3 \\
\hline Cheilodactylus quadricornis & & 1 & & \\
\hline Cirrhitichthys aureus & 8 & & & \\
\hline Platax teira & & 2 & 8 & 3 \\
\hline Parapristipoma trilineatum & 15 & 120 & 50 & 30 \\
\hline
\end{tabular}


Table 6. (continued)

\begin{tabular}{|c|c|c|c|c|}
\hline Species & Artifical reefs & wind tower & wind turbine\#1 & wind turbine\#2 \\
\hline Kyphosus cinerascens & & 1 & & \\
\hline Microcanthus strigatus & 2 & & 2 & 3 \\
\hline Bodianus diana & & 1 & & \\
\hline Choerodon azurio & & & 1 & \\
\hline Halichoeres poecilepterus & & & 3 & \\
\hline Labroides dimidiatus & & 3 & 2 & 1 \\
\hline Thalassoma lutescens & & & 1 & 1 \\
\hline Leiognathus spp & 100 & & & \\
\hline Lutjanus fulviflamma & & 3 & 3 & 3 \\
\hline Lutjanus monostigma & & 8 & & 1 \\
\hline Lutjanus vitta & & 3 & 6 & 4 \\
\hline Caesio caerulaurea & & 100 & & \\
\hline Pterocaesio digramma & 1 & 50 & 10 & 5 \\
\hline Monodactylus argenteus & & & 1 & \\
\hline Gymnothorax favagineus & & & 1 & \\
\hline Scolopsis vosmeri & & 5 & 4 & 4 \\
\hline Oplegnathus punctatus & 1 & 1 & & \\
\hline Chaetodontoplus septentrionalis & & 2 & 1 & \\
\hline Pomacanthus semicirculatus & & 1 & & \\
\hline Abudefduf vaigiensis & & 10 & 5 & 20 \\
\hline Chromis fumea & & 10 & 10 & \\
\hline Neopomacentrus cyanomos & 30 & 800 & 200 & 100 \\
\hline Ilisha melastoma & 30 & & & \\
\hline Pterois volitans & & 1 & & \\
\hline Sebastiscus marmoratus & 1 & & & \\
\hline Cephalopholis boenak & 1 & 1 & 1 & 2 \\
\hline Sphyraena flavicauda & 50 & 150 & 50 & 50 \\
\hline Zanclus cornutus & & 2 & & \\
\hline
\end{tabular}

Fish length $(\mathrm{cm})$

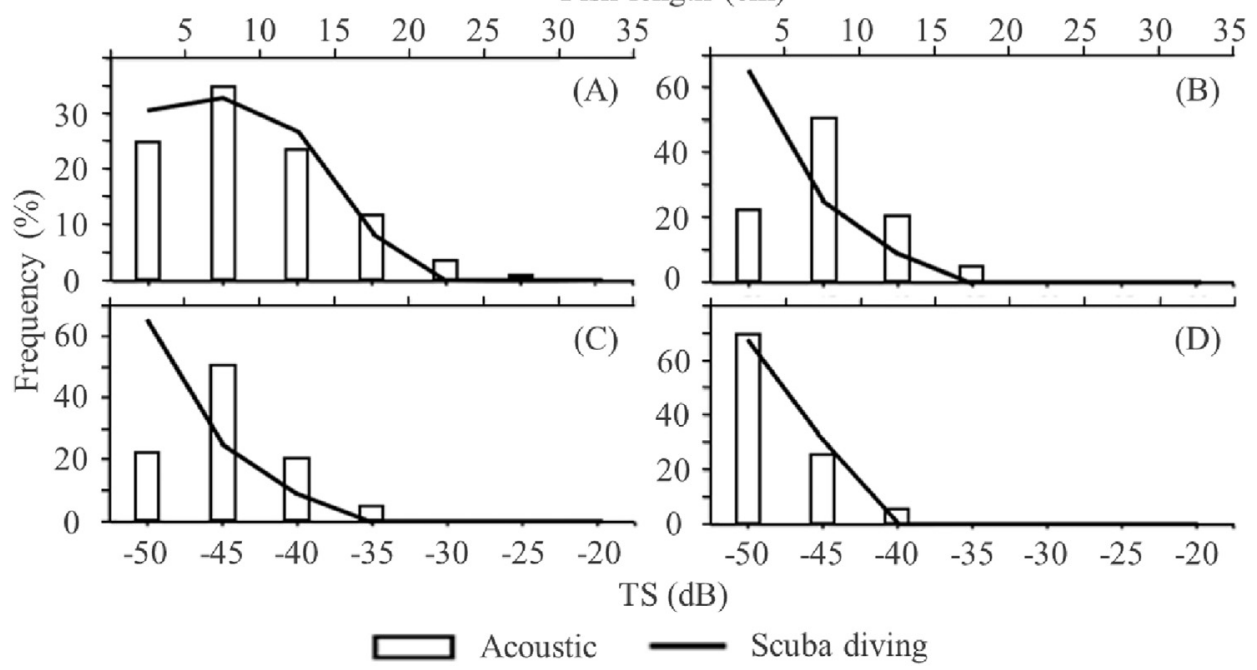

Fig. 7. Fish length distribution obtained by scuba diving and acoustic estimation (transformed by TS $=19.1 \log L+0.9 \log \lambda-34.2$ [18]). (A) Artificial reefs; (B) Wind tower; (C) Wind turbine \#1; (D) Wind turbine \#2.

survey, transducer usually faced toward sea bottom, therefore TS information were mainly base on dorsal aspect of fish $[6,8,18,21]$. The study by Bosswell (2008) [31] for side-aspect target strength measurements of bay anchovy (Anchoa mitchilli) and Gulf menhaden (Brevoortia patronus) also found that TS has a higher value on the side-aspect. The study also suggested that the availability of side-aspect TS can be increased by the adjustment of pulse duration.

In the tank experiment, we confirmed that the linearity between TS and fish length reduce gradually from vertical to horizontal detection (Fig. 6). Tilt 


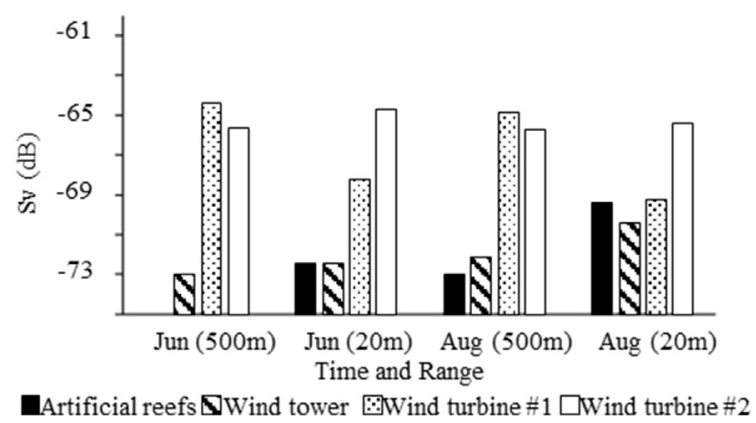

Fig. 8. Comparison of fish aggregation by volume backscattering strength (Sv) among four facilities in Nanlong wind farm area.

beam angles from $30^{\circ}$ and $60^{\circ}$ are applicable in insitu surveys. We used $60^{\circ}$ in the in-situ survey because considering the vessel size and water depth in the wind farm area. Fig. 9 shows some examples of echograms with tilt angles of $60^{\circ}$. In surface water, tilt beam angle can effectively reduce the dead zone of the surface water near the wind facilities. The design of special trackline and the use of tilt beam angles are suitable for acoustic survey around the wind turbine. However, when taking the advantage of tilt beam survey near obstacle waters like wind farm area, the problem of increased dead zone near the sea bottom need to be considered seriously. As shown in Tables 4 and 5, the wind tower and the wind turbine\#1, scuba diving observed a large number of fishes less than $5 \mathrm{~cm}$, but they may hide in the dead zone of acoustic detection, which resulting in big inconsistence of length distribution (Fig. 7). Our consideration will be given to using both vertical and tilted beams to reduce the impact of acoustic dead zone in future studies. However, TS-related research about side-aspect is still insufficient in Nanlong wind farm area, also that may cause deviation in length estimation, and TS formula based on the side-aspect needs to be discussed in more depth in order to research the horizontal detection data more completely.

Surveys conducted by Hvidt et al [12]. in wind farm area using tilt beam angle and actual catches confirmed there were no expectation of any negative effects by wind turbines. In this study, we found that wind facilities have a better fish aggregation effect than artificial reef (Fig. 8), both wind turbines has higher Sv values, whether at a distance of $20 \mathrm{~m}$ or $500 \mathrm{~m}$ from the facility. The results of acoustic survey directly show fish aggregation effect of the two wind turbines. The species and abundance information obtained by scuba diving within $20 \mathrm{~m}$ of the wind turbines also prove the aggregation effect, which including some fish hidden in acoustic dead zone (Tables 4 and 5). Wilhelmsson et al [30]. suggested that offshore wind farms can aggregate small demersal fish according to their scuba diving observation. The present study first attempt to study
(A)

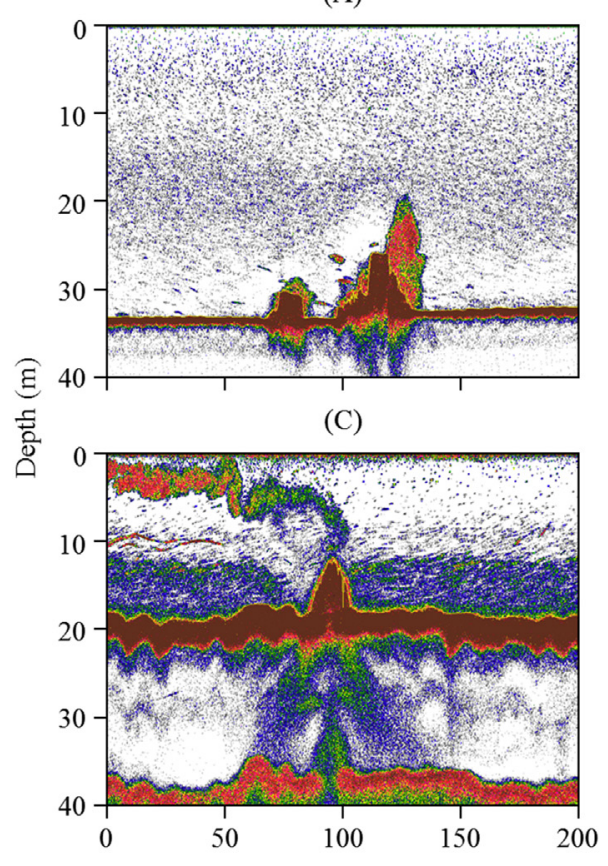

(B)

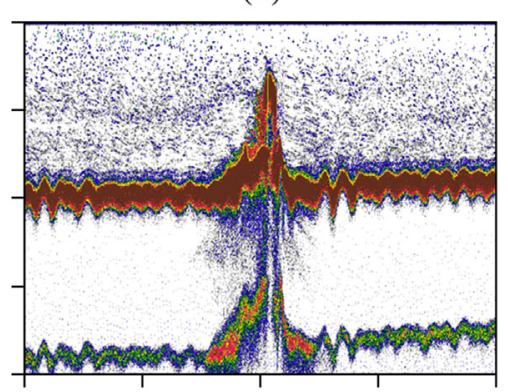

(D)

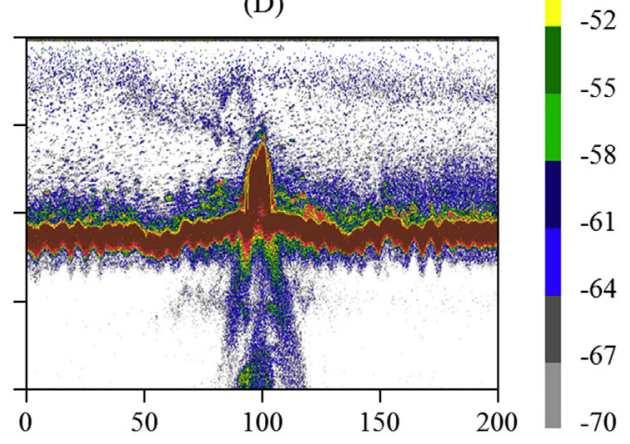

$\mathrm{Sv}(\mathrm{dB})$

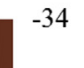

$-37$

$-40$

$-43$

$-46$

$-49$

$-52$

$-55$

$-58$

$-61$

$-64$

$-67$

$-70$

Range (m)

Fig. 9. Echograms of four facilities detected by tilt angle of $60^{\circ}$. (A) Artificial reefs; (B) Wind tower; (C) Wind turbine\#1; (D) Wind turbine\#2. 
fish aggregation effect of wind turbines by joint surveys of both acoustic and scuba diving.

The two wind turbines were only constructed about 1 year before the acoustic surveys. The following are the possible factors causing wind facilities have relative better performance of fish aggregation: (1) The artificial reefs are too old, so the fish aggregation effect is getting lost. The artificial reef surveyed was set in February 2004, which has been 15 years old. The artificial reefs are disintegrating and collapsing, the fish aggregation effect has gradually degraded $[27,28]$. (2) When setting up offshore wind facilities, a flushing protection design was set up at surrounding of the bottom to protect the base of the wind turbines. These structures also formed habitat space for fish to enhance the effect of the fish aggregation.

According to the government's wind power development plan, thousands of offshore wind turbines will be built in the western of Taiwan in the future. It is necessary to use more independent fishery surveys and acoustic survey by scientific echosounder will be one of them. The survey method developed in this study can be applied in more new constructed wind turbines. When large cluster of wind turbine are formed, for navigation safety it will be more necessary to use tilt beam when conducting acoustic survey across the matrix of wind turbines.

\section{Acknowledgement}

This study was supported the Ministry of Science and Technology (MOST 107-2119-M-110-001- and MOST 108-2611-M-019-001 -), Taiwan.

\section{References}

[2] Bureau of Energy, Ministry of Economic Affairs. 4-year promotion plan for wind power generation, 106 National Power Supply and Demand Report. 2017. p. 22 (in Chinese).

[3] Carrasco JM, Franquelo LG, Bialasiewicz JT, Galván E, PortilloGuisado RC, Prats MAM, Moreno-Alfonso N. Powerelectronic systems for the grid integration of renewable energy sources: A survey. IEEE Trans Ind Electron 2006;53(4): 1002-16.

[4] De Troch M, Reubens JT, Heirman E, Degraer S, Vincx M. Energy profiling of demersal fish: A case-study in wind farm artificial reefs. Marine environmental research 2013;92: 224-33.

[5] Dunlop ES, Reid SM, Murrant M. Limited influence of a wind power project submarine cable on a Laurentian Great Lakes fish community. J Appl Ichthyol 2016;32(1):18-31.

[6] Fleischer GW, Argyle RL, Curtis GL. In situ relations of target strength to fish size for Great Lakes pelagic planktivores. Trans Am Fish Soc 1997;126(5):786-94.

[7] Godlewska M, Frouzová J, Kubecka J, Wiśniewolski W, Szlakowski J. Comparison of hydroacoustic estimates with fish census in shallow Malta Reservoir-which TS/L regression to use in horizontal beam applications? Fish Res 2012; 123-124:90-7.
[8] Gurshin CWD. Target strength measurements of juvenile blueback herring from the Mohawk River, New York. North Am J Fish Manag 2012;32(2):381-6.

[10] Harvey E, Fletcher D, Shortis M. Estimation of reef fish length by divers and by stereo-video: a first comparison of the accuracy and precision in the field on living fish under operational conditions. Fish Res 2002;57(3):255-65.

[11] Hooper T, Beaumont N, Hattam C. The implications of energy systems for ecosystem services: a detailed case study of offshore wind. Renew Sustain Energy Rev 2017;70: 230-41.

[12] Hvidt CB, Leonhard SB, Klaustrup M, Pedersen J. Hydroacoustic monitoring of fish communities in offshore wind farms. Horns Rev Offshore Wind Farm Annu Rep 2006:54.

[14] Knudsen FR, Sægrov H. Benefits from horizontal beaming during acoustic survey: application to three Norwegian lakes. Fish Res 2002;56(2):205-11.

[15] Kubecka J, Wittingerova M. Horizontal beaming as a crucial component of acoustic fish stock assessment in freshwater reservoirs. Fish Res 1998;35(1-2):99-106.

[16] Kurnia M, Iida K, Mukai T. Characteristics of three-dimensional target strength of swim bladdered fish. The Journal of the Marine Acoustics Society of Japan 2012;39(3):93-102.

[17] Lilja J, Keskinen T, Marjomäki TJ, Valkeajärvi $P$ Karjalainen J. Upstream migration activity of cyprinids and percids in a channel, monitored by a horizontal split-beam echosounder. Aquat Living Resour 2003;16(3):185-90.

[18] Love RH. Dorsal-aspect target strength of an individual fish. J Acoust Soc Am 1971;49(3B):816-23.

[19] MacLennan DN. Acoustical measurement of fish abundance. J Acoust Soc Am 1990;87(1):1-15.

[21] Mehner T, Gassner H, Schulz M, Wanzenböck J. Comparative fish stock estimates in Lake Stechlin by parallel splitbeam echosounding with $120 \mathrm{kHz}$. Arch Hydrobiol Spec Issues Adv Limnol 2003;58:227-36.

[22] Marchal E, Petitgas P. Precision of acoustic fish abundance estimates: separating the number of schools from the biomass in the schools. Aquat Living Resour 1993;6(3):211-9.

[23] Ohshimo S. Acoustic estimation of biomass and school character of the Japanese anchovy Engraulis japonica in the East China Sea and the Yellow Sea. Fish Sci 1996;62(3):344-9.

[24] Reubens JT, Pasotti F, Degraer S, Vincx M. Residency, site fidelity and habitat use of Atlantic cod (Gadus morhua) at an offshore wind farm using acoustic telemetry. Marine Environmental Research 2013;90:128-35.

[25] Rodríguez-Sánchez V, Encina-Encina L, Rodríguez-Ruiz A, Monteoliva A, Sánchez-Carmona R. Horizontal target strength of Cyprinus Carpio using $200 \mathrm{kHz}$ and $430 \mathrm{kHz}$ split-beam systems. Fish Res 2016;174:136-42.

[26] Rose GA. A review of problems and new direction in the application of fisheries acoustics on the Canadian East Coast. Fish Res 1992;14(2-3):105-28.

[27] Shao KT, Lu HJ, Huang JS, Chen TJ, Lin SM, Wu SP. Biological survey in artificial reefs and aquatic breeding and protection zones in northern Taiwan. 2018 project report of Fishery Agency. Council of Agriculture; 2018. p. 219 (in Chinese).

[28] Shao KT, Lu HJ, Huang JS, Chen TJ, Lin SM, Wu SP, Lin CW. Biological survey in artificial reefs and aquatic breeding and protection zones in northern Taiwan. 2019 project report of Fishery Agency. Council of Agriculture; 2019. p. 219 (in Chinese).

[29] Simas M, Pacca S. Assessing employment in renewable energy technologies: A case study for wind power in Brazil. Renew Sustain Energy Rev 2014;31:83-90.

[30] Wilhelmsson D, Malm T, Öhman MC. The influence of offshore windpower on demersal fish. ICES J Marine Sci 2006;63(5):775-84.

[31] Side-aspect target-strength measurements of bay anchovy (Anchoa mitchilli) and Gulf menhaden (Brevoortia patronus) derived from ex situ experiments. ICES J Marine Sci 2008; 65(6):1012-20. 